\title{
Bees associate warmth with floral colour
}

\section{Pollinators may be seeking more than just food as a reward when they choose one flower over another.}

Floral colour signals are used by pollinators as predictors of nutritional rewards, such as nectar ${ }^{1-3}$. But as insect pollinators often need to invest energy to maintain their body temperature $^{4}$ above the ambient temperature, floral heat might also be perceived as a reward. Here we show that bumblebees (Bombus terrestris) prefer to visit warmer flowers and that they can learn to use colour to predict floral temperature before landing. In what could be a widespread floral adaptation, plants may modulate their temperature to encourage pollinators to visit.

Some beetles spend extended periods (about 24 hours) inside specialized thermogenic flowers, even in the absence of a nutritional reward ${ }^{5}$, and basking insects will take advantage of floral suntraps ${ }^{6}$. Visits to flowers by pollinating insects in order to imbibe carbohydrates in nectar are typically much briefer. But it is possible that endothermic pollinators might also seek a metabolic reward in the form of heat, given that the temperature of floral nectar is the same as the flower containing it. Differences in floral temperature occur widely between and within plant species ${ }^{6-9}$ and, if these variations can influence the preference of pollinators,

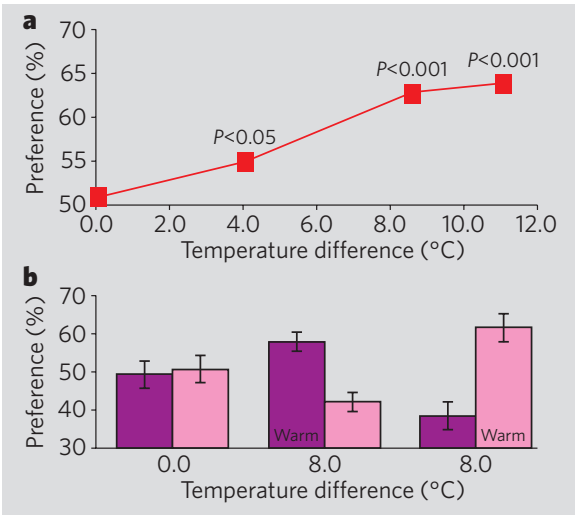

Figure 1 | Temperature preferences and flowercolour use by bees. a, Bee preference for sucrose solution at different temperatures above room temperature $\left(18.5^{\circ} \mathrm{C}\right)$; $P$ values for $\chi^{2}$; d.f. $=1$. b, Bees learn to associate colour with temperature: when purple flowers are warmer than pink flowers by $8{ }^{\circ} \mathrm{C}$, bees prefer the warmer purple flowers (central column pair); when pink flowers are warmer, these are chosen more often (right column pair). When there is no temperature difference, bees show no preference for either colour (left column pair). For each bee 100 choices were evaluated, and ten bees were used per group.

pollinators may forage adaptively by paying attention to temperature when choosing between flowers ${ }^{10}$.

To test whether warmer nectar is preferred by pollinators, we connected a bumblebee nest box to a flight arena where sucrose solution ( $20 \%$ by volume) was available from two identical feeders, one at room temperature $\left(18.5^{\circ} \mathrm{C} \pm 0.3\right.$ s.d. $)$ and the other at $18.5^{\circ} \mathrm{C}, 22.5^{\circ} \mathrm{C}$, $27^{\circ} \mathrm{C}$ or $29.5^{\circ} \mathrm{C}$ (for details, see supplementary information). There was a significant increase in bees' preference for the warmer feeder (Pearson's $R=0.9870, P=0.012$ ), and this preference was significant

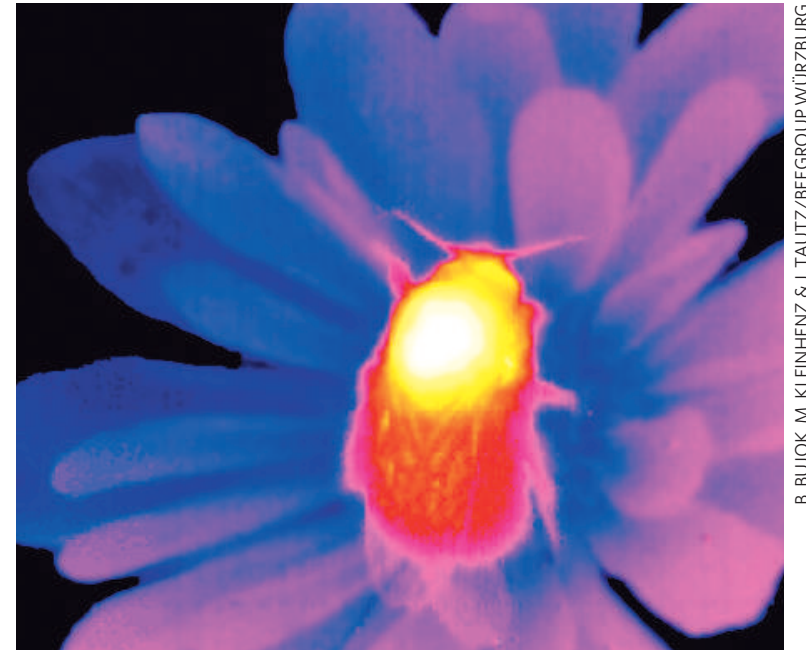

Hot spot: a thermographic image of a bumblebee taken with an infrared camera - brightness indicates higher temperature. when the temperature differ-

ence was $4{ }^{\circ} \mathrm{C}$ or more (Fig. 1a). In this case, bees were using spatial positioning to identify the warmer feeder.

To test whether bees can learn to use flower colour to identify warmer flowers, we exposed them to coloured artificial flowers (four purple 'flowers' at $28.8 \pm 0.2{ }^{\circ} \mathrm{C}$ and four pink 'flowers' at $20.8 \pm 0.1^{\circ} \mathrm{C}$ ), which were positioned randomly and which each presented $20 \mu$ l sucrose solution ( $40 \%$ by volume) (see supplementary information).

Choice frequency for bees landing on the warmer purple flowers was 58.0\% $( \pm 2.6$ s.d.; $\chi^{2}=25.6$, d.f. $=1, P<0.001 ; n=10$ bees) (Fig. 1b). This was significantly higher than the choice frequency in a control group, for which there was no temperature difference between the purple and pink flowers, and indicates that the bees did not simply prefer purple flowers (Fig. 1b; mean, $49.4 \% \pm 3.0$ s.d.; independent samples $t$-test, $t=9.54$, d.f. $=18, P<0.001$; $n=10$ bees per treatment). When the pink flowers were warmer than the purple ones, the pink colour was preferred (Fig. 1b; mean, $61.6 \% \pm 3.8$ s.d.; $\chi^{2}=53.8$, d.f. $=1, P<0.001 ; n=10$ bees).

We conclude that the bees preferred to land on the warmer flowers, even though the similarly coloured alternative contained the same nutritional reward. In another control experiment in which flowers varied in temperature but not colour, discrimination fell to chance levels $\left(50.8 \% \pm 3.1\right.$ s.d.; $\chi^{2}=0.3$, d.f. $=1 ; P=0.64$, NS; $n=10$ bees), indicating that the bees must use colour as a cue, rather than directly gauging temperature by remote perception.

Our findings indicate that floral temperature can serve as an additional reward for pollinator insects when nutritional rewards are also available. They may also have implications for the evolution of specific floral structures and for the connection between floral sensory cues, floral temperature and pollinator behaviour?

Adrian G. Dyer ${ }^{\star}$, Heather M. Whitney ${ }^{\star}$,

Sarah E. J. Arnold ${ }^{\star}$, Beverley J. Glover ${ }^{\star}$, Lars Chittka†

*Department of Plant Sciences, University of Cambridge, Cambridge CB2 3EA, UK

$\uparrow$ Biological and Chemical Sciences, Queen Mary College, University of London, London E1 4NS, UK e-mail:I.chittka@qmul.ac.uk

1. Menzel, R. \& Backhaus, W. in The Perception of Colour (ed. Gouras, P.) 262-293 (Macmillan, London, 1991)

2. Chittka, L., Dyer, A. G., Bock, F. \& Dornhaus, A. Nature 424, 388 (2003)

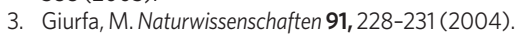

4. Heinrich, B. \& Esch, H. Am. Sci. 82, 164-170 (1994)

5. Seymour, R. S., White, C. R. \& Gibernau, M. Nature 426, 243-244 (2003).

6. Kevan, P. G. Science 189, 723-726 (1975)

7. Sapir, Y., Shmida, A. \& Ne'eman, G. Oecologia 147, 53-59 (2006).

8. Miller, G. A. Oecologia 70, 155-160 (1986)

9. Comba, L. et al. Plant Cell Environ. 23, 639-647 (2000)

10. Thien, L. B., Azuma, H. \& Kawano, S. Int. J. Plant Sci. 161 (suppl.), 225-235 (2000).

Supplementary information accompanies this communication on Nature's website.

Received 6 April; accepted 30 June 2006. Competing financial interests: declared none. doi:10.1038/442525a 